\title{
Person-Environment Fit and Retention of Racially Minoritized College Students: Recommendations for Faculty, Support Staff, and Administrators
}

\author{
Alex A. Ajayi ${ }^{1, *}$, Lauren L. Mitchell ${ }^{2}$, Sarah C. Nelson ${ }^{3}$, Jillian Fish ${ }^{3}{ }^{(D}$, Lovey H. M. Peissig ${ }^{3}$, José M. Causadias ${ }^{4}$ \\ and Moin Syed ${ }^{3}$ \\ 1 Department of Psychology, Augsburg University, Minneapolis, MN 55454, USA \\ 2 Department of Psychology, Emmanuel College, Boston, MA 02115, USA; mitchell1@emmanuel.edu \\ 3 Department of Psychology, University of Minnesota, Minneapolis, MN 55455, USA; \\ morr0830@umn.edu (S.C.N.); Fishx174@umn.edu (J.F.); walke871@umn.edu (L.H.M.P.); \\ moin@umn.edu (M.S.) \\ 4 School of Social and Family Dynamics, Arizona State University, Tempe, AZ 85287, USA; \\ jose.causadias@asu.edu \\ * Correspondence: ajayi@augsburg.edu
}

check for

updates

Citation: Ajayi, A.A.; Mitchell, L.L.; Nelson, S.C.; Fish, J.; Peissig, L.H.M.; Causadias, J.M.; Syed, M.

Person-Environment Fit and

Retention of Racially Minoritized College Students: Recommendations for Faculty, Support Staff, and Administrators. Educ. Sci. 2021, 11, 271. https://doi.org/10.3390/ educsci11060271

Academic Editor: Eleanor Dommett

Received: 1 May 2021

Accepted: 24 May 2021

Published: 31 May 2021

Publisher's Note: MDPI stays neutra with regard to jurisdictional claims in published maps and institutional affiliations.

Copyright: (c) 2021 by the authors. Licensee MDPI, Basel, Switzerland. This article is an open access article distributed under the terms and conditions of the Creative Commons Attribution (CC BY) license (https:// creativecommons.org/licenses/by/ $4.0 /)$.

\begin{abstract}
Although colleges in the United States have become increasingly racially and ethnically diverse, degree attainment remains disproportionately low among students from underrepresented and minoritized racial backgrounds. In this paper, we discuss the interactive influence of both person and environment factors in shaping academic persistence and argue that college administrators, faculty, and student support staff can intervene and take specific steps to improve the academic experience of racially minoritized college students. To this end, we offer specific evidence-based recommendations for campus leaders and stakeholders on how to adapt their campus community to facilitate the requisite person-environment fit to maximize academic persistence.
\end{abstract}

Keywords: underrepresented students; retention; student affairs; education achievement; instruction

Higher education is often viewed as the great equalizer-a way of achieving the American Dream and social mobility [1]. As late as the 1960s, students of color were categorically excluded from attending many colleges and universities in the United States [2]. Despite the strides since the signing of the Civil Rights Act of 1964, which desegregated schools, persistent racial disparities in degree attainment suggest that higher education for underrepresented and racially minoritized college (URM) students remains separate and unequal [3]. Of note, we use the term "racially minoritized" instead of "racial minority" to reflect that social stratification based on race in the United States is rooted in systems of power and privilege rather than simply demographic proportions. To be sure, a lot has changed since the 1960s. In the context of the COVID-19 pandemic and uprisings for racial justice, early data suggest that many elite universities across the country accepted the highest number of URM students in their histories [4]. As college campuses become increasingly diverse, institutions need to confront their troubled pasts related to race. They also need to reconcile their current shortcomings in providing adequate and equitable opportunities for URM students to thrive and succeed, as these students continue to leave college early at troubling rates [5].

Researchers and educators have argued for decades that increasing the participation and retention of URM students should be a major priority in higher education [6]. College graduation is one of the biggest drivers of the growing wealth gap along racial lines with farreaching implications on labor market variables (e.g., earned income, employer-provided workplace benefits, and unemployment) [7]. Eliminating disparities in higher education attainment is also one of the ways the U.S. can reckon with the legacy of structural racism in this country. Structural racism refers to the process by which racial discrimination is 
maintained, through mutually reinforcing systems of inequality in housing, education, criminal justice, health care, employment, and so on [8].

Education scholars have suggested that the curriculum and culture of higher education create an inhospitable environment for many URM students that cause many to leave [9]. URM students report facing racial discrimination, social exclusion, microaggressions, and the task of resisting deficit-oriented cultural stereotypes [10]. These experiences have been shown to decrease their sense of belonging on campus and persistence in educational environments [11,12]. Students also need to contend with the rhetoric about their experiences. One of the ways in which systems of inequality are maintained is through centering interventions and programming on changing and equipping students, rather than changing the institutions that maintain the racial gap in degree attainment. Indeed, the majority of the available literature on URM student retention focuses on either what students can do or what universities can do $[13,14]$. We attempt to bridge these bodies of literature, using person-environment fit as a theoretical framework for understanding URM students' decisions to stay or leave college early $[15,16]$. Finally, we provide specific recommendations based on the available literature on what faculty, student affairs and academic support staff, and institutional administrators can do to help URM students graduate.

\section{Retention of URM Students in Context}

The term URM students typically refers to Black/African Americans, Latinxs/Hispani cs, and Indigenous peoples (e.g., American Indian/Alaska Native, Native Hawaiian) who at a national level have college graduation rates that are disproportionately lower than their White counterparts. Available data show that approximately 74 percent of Asian students and 64 percent of White students graduated with a bachelor's degree or its equivalent within six years, compared with 60 percent of students of two or more races, 54 percent of Hispanic students, 54 percent of Pacific Islander students, 40 percent of Black students, and 39 percent of students who identify as American Indians/Alaska Natives [17].

It is important to note that although aggregated statistics suggest Asian students perform better than any other racial group, scholars have cautioned that such a conclusion betrays the heterogeneity of this group [18]. Many ethnic groups subsumed under the category of Asian/Pacific Islander experience notable disadvantages in educational outcomes that become invisible by their aggregation in one category [19]. Thus, as we might expect, the statistics do not fully describe the state of ethnic disparities in education. This example of intergroup complexity suggests the importance of developing a nuanced understanding of educational disparities, which can inform concrete intervention efforts towards decreasing retention inequality. When possible, specific grouping variables should be considered when examining ethnic disparities in education (e.g., Mexican American rather than Latinx/Hispanic, Korean American rather than Asian American, Lakota rather than American Indian). We encourage the reader to critically examine the groups of students who are underrepresented and under-resourced at a particular university in light of the organized system of social stratification (e.g., based on race and ethnicity). This inclusive and contextual approach acknowledges how URM students may comprise different configurations of racial and ethnic groups at different institutions. It is essential that scholars and university stakeholders understand who URM students are on their campuses and lead efforts to retain them.

Universities need to make retention of URM students a priority for two reasons. First, college attrition of URM students is one of the many manifestations of inequitable distribution of power and privilege that exists throughout society and social institutions. Compared to their peers who earn their degrees, college students who drop out are more likely to default on their student debt, live in poverty, and have less lifetime earnings [20]. In addition to the negative impacts on students, dropping out also has critical implications for universities and broader communities. In addition to loss of tuition revenue for institutions, state and federal governments spend billions of dollars to help pay for the education 
cost of students who drop out [21]. As such, we consider retention of URM students a public policy and social justice issue, fundamental to combating systemic inequalities and structural racism and fostering a thriving society.

Second, we expect the retention of URM students to contribute to better educational and research outcomes for higher education institutions. A growing body of literature suggests that racially diverse groups and classrooms perform better than those less diverse because diverse groups offer a range of perspectives and skills that can be applied to complex tasks [22,23]. Beck [24] demonstrated the applicability of this principle to the college classroom. Analyzing the discussions of ethnically diverse classes and all-White classes, he found that diverse classes exhibited greater student participation in terms of the number of words spoken by students, the number of students active in the discussion, and the percentage of student-to-student interactions [24]. Furthermore, beneficial effects of diversity can be found in the context of research. In a study of over 1.5 million scientific papers, researchers found that articles written by ethnically heterogeneous research teams tended to be published in higher impact journals and receive more citations than those written by ethnically homogenous groups [25].

In addition to perpetuating systems of inequality, colleges that do not actively work to promote diversity may deprive their students, faculty, and staff of opportunities to form high-performing diverse groups and partnerships, limiting their potential impact. Now more than ever, it is critical to level the playing field and to have educational contexts that reflect the multicultural realities of our diversifying nation in terms of people and perspectives. Indeed, the COVID-19 pandemic and uprisings for racial justice have shed much-needed light on the pervasive, structural racial inequities in all sectors of the United States, including in higher education. It also made urgent the need to address these deepseated inequities in our society and shortcomings in building an inclusive democracy in substantive ways.

\subsection{Person-Environment Fit Framework}

Efforts that address the attrition of URM students must begin with the identification and understanding of factors contributing to student persistence. Student retention remains one of the most studied areas of higher education in the last few decades. This extensive body of literature has proposed numerous factors related to the "leaks" of URM students in the higher education pipeline [26-28]. Ultimately, there seems to be a dynamic interaction between personal attributes and environmental influences in explaining student academic persistence [29]. For instance, Tinto [28,30] described this interactive relationship between person and environment in a theoretical framework for retention that posits that student personal characteristics (e.g., motivation, prior achievement, ability) interact over time with the formal and informal academic and social aspects of the college environment. As such, the degree to which students are socially and academically integrated into their campus environment will determine their decision to stay in college or to leave before graduation. As students arrive on campus, they begin to ascertain how well they will fit in with the institution's social and academic systems. The more students perceive compatibility between their personal characteristics and their campus, the greater the sense of integration [30]. This integration is believed to be temporally sensitive, such that students who fail to become integrated during the first year are more likely to drop out $[28,30,31]$. Empirical studies have begun to support these theoretical postulations that college persistence is predicated on the correspondence between students and their academic environments. These research findings underscore, for example, the importance of integration between ethnic-racial and academic identities in terms of both educational commitment and a sense of belonging on campus [32,33].

In adopting the perspective that student retention depends on the fit between the student and the environment, we find that much of the existing literature focuses only on one-half of the equation. That is, the traditional approach to addressing student retention mainly focuses on either characteristics of the students (e.g., academic achievement and 
aptitude [34]; motivation and self-concept [35]; demographic and socioeconomic characteristics [36]; health behaviors, coping skills, and prior academic record [37]) or characteristics of the university (e.g., financial aid allocation [38]; campus culture [39]; mentorship programs [40]; academic success courses [31]). Furthermore, college administrators tend to attribute student attrition to personal characteristics of the students rather than characteristics of the institution [41]. Unfortunately, this traditional approach ignores dynamic interactions between students' identities and the environment (e.g., institutional policy, campus climate, and classroom experiences) that affect students' decisions to stay or leave early. As a result, actions meant to support retention are often taken without considering these interactions, and consequently, these actions are less likely to succeed.

Although our recommendations are aimed at actors within institutions, they address person-environment fit because they are centered around the qualities and needs of URM students within a particular institution. Rather than providing broad institutional recommendations, we emphasize specific ways that faculty, student support professionals, and administrators can develop an approach that is attuned to their own institution's URM students. Effectively engaging these strategies will require institutional actors to evaluate their own local context and consult directly with URM students at their institution to guide their approach. Recognizing that students also shape their environments, we highlight opportunities for faculty, staff, and administrators to empower URM students to influence the institution as well. By placing emphasis on these actors and not students, we recognize the racialized labor URM students are subjected to as they navigate oppressive systems, including higher education [42]. Smith [43] introduced the concept of racial battle fatigue in higher education, arguing that universities are rooted in White supremacy. In this environment, URM students are confronted with how White privilege and the inherent valuation of Whiteness are embedded in the culture of higher education [44]. The accumulation of race-related stressors is thought to leave URM students psychologically, physiologically, and behaviorally taxed. As such, the task of making environments more facilitative for URM students to thrive falls in a large part on the shoulders of non-student campus change agents, especially those who are not URM.

\subsection{Emerging Adulthood and the Relevance of Developmental Tasks}

It is likely that factors that promote college adjustment and ultimately determine retention among URM students can also be conceptualized within a developmental framework. Emerging adulthood is theperiod from late teens through the twenties that coincides with the traditional college-age [45] and characterized by multiple developmental milestones that may affect college adjustment [46-48]. Additionally, emerging adulthood has been proposed as a new stage of life that has not been experienced in previous generations. In the past, many young adults were married, had children, and had entered a long-term career by their early twenties, whereas emerging adults in our era tend to postpone these commitments to spend time exploring options. Identity exploration has emerged as a central defining feature of emerging adulthood in the United States [46-48], across domains such as work, love, worldview, sexuality [49], and racial-ethnic identity [50-52].

College may provide an ideal environment for identity exploration, as students are exposed to a variety of courses, extracurricular activities, role models, and peers $[53,54]$. For URM students, however, college may not be seen as an ideal environment for identity exploration, especially if they are met with hostility, neglect, and discrimination. As mentioned earlier, a sense of attachment and integration into the college campus is critical to student retention [26,30], as those who feel they do not belong are more likely to leave. It appears that students' perceptions of alignment between their identity and their college environment play an important role in their decision to stay or leave early.

Contextual factors associated with college adjustment and retention have not received theoretical and empirical parity with individual factors in the extant literature. As a result, relatively little is known about how specific campus environments can facilitate or constrain academic persistence. In our evidence-based recommendations, we aim 
to address this gap in the literature, enumerating several concrete steps that colleges and universities can take to support URM students, considering what we know about predictors of adjustment and wellbeing among URM students. To take into account both the person and the environment sides of the equation, the actions we recommend must be adapted to each university's unique student body, targeting students on campus less likely to graduate. As discussed earlier, URM students may include different ethnicracial groups in different parts of the country and world (i.e., international students). It is the responsibility of university administrators, faculty, and staff to determine the characteristics of their own students and adapt these strategies to their unique situation in order to promote person-environment fit among their URM students. We particularly focus on these three institutional agents because institutions are not social actors and do not behave; however, university administrators, faculty, and staff do behave, and we argue that their behaviors can be instrumental in fostering success among URM students. Indeed, past work has identified these particular agents as vital to the continued success and wellbeing of academic institutions [55].

\subsection{Environmental Considerations and Strategies for Fostering Academic Success among URM Students}

There are many ways in which academic institutions can foster students' sense of connectedness to their campus environment. These efforts can be organized into different spheres of influence, particularly in the domains of instruction, campus life, and institutional governance. Although these three related domains are far from exhaustive, they represent important places institutions can direct their attention and resources in efforts to meet the needs of their diverse students and specifically redress some of the barriers URM students face in their pursuit of academic success. Ultimately, the crux of the task institutions face is to create and sustain a campus environment that is not only inclusive but also affirming-providing all students, regardless of socio-cultural background, a space to achieve their highest potential and complete college. Since students' academic achievement is often influenced by their appraisal of their environment, it is integral that institutions displace some of the onus of academic success from the students and assume greater responsibility for fostering a campus environment conducive to success. Thus, we offer suggestions for faculty to incorporate in their instruction, student affairs and academic support staff to consider in their programming, and administrators in structuring their campuses.

\section{Instruction and Mentorship: Considerations and Action Points for Faculty}

Contact with faculty is one of the most important factors for success in college [56]. Through their roles as instructors and mentors, faculty members are uniquely positioned to combat attrition through direct relationships with students. Empirical work suggests that engaging and approachable faculty can contribute to URM students' persistence in college, whereas a lack of positive interactions with faculty can contribute to decisions to leave college [57]. Indeed, for URM students, interactions with faculty may contribute more to learning than for White students [58].

\subsection{Increase the Quantity and Quality of Formal and Informal Interactions with Students That Aim to Promote Positive Identity Development}

A substantial body of research reveals that academic success and satisfaction among URM students are influenced by formal and informal exchanges with instructors, both in and out of the classroom. Quantity of contact alone does not seem to promote academic success [59-61]; rather, faculty need to consider the quality of their interactions with students. Beneficial interaction can come in a variety of forms (as we discuss below). Regardless of the particular activities taking place, there are several underlying factors that most positive student-faculty interactions have in common. Namely, faculty who respect students' values, affirm students' capabilities, and show sincere interest in students' contributions seem to best foster student success [62-64]. By treating students as valuable members of 
the academic community, professors can encourage the development of students' academic identities. As identity development is a central developmental task for young adults [47], faculty who can facilitate academic identity development for URM students may have the strongest impact on their academic careers. For instance, Cole [65] found that African American and Latino students who experienced student-faculty relationships that reflected emotional support and encouragement, respect, and intellectual challenge performed better academically and were more satisfied with their education.

Specific activities that may fit with this goal of promoting positive identity development among URM students may include: participation in undergraduate research programs that involve a high degree of responsibility and contact with faculty [66,67]; incorporating group work that encourages interaction among diverse peers (though, researchers caution against spreading URM students too thinly among groups to avoid creating the dynamic of a single "token" URM student among an otherwise White group) [62]; employing a wide variety of teaching methods such as lecture, large and small group discussion, student presentations, and hands-on laboratory activities rather than repeatedly using just a few methods [68]; providing "accessibility cues" or signals during class that invite students to further contact outside the classroom [59]; designing coursework that engages students' personal cultural background [69] and directly addressing issues of culture in class discussion and activities [26,62].

\subsection{Offer Mentorship Opportunities for URM Students}

In a study by Kricorian and colleagues [70], URM students highlighted the importance of meeting and being mentored by individuals who were matched in terms of gender or race, either in person or through media representation. Faculty can help facilitate opportunities for students to have interactions with matched-background mentors as much as possible. When not possible, the authors underscore the potential value of using inclusive media to showcase the accomplishments of diverse voices in the respective disciplines. Faculty development training could also involve best practice discussions and tips on how to effectively engage and connect with students. Such events could include personal and research presentations about the values of meaningful interactions with students in and out of the classroom as well as information on opportunities for such engagements (e.g., student organization advising).

\subsection{Use Intersectionality as a Lens to Understand URM Students' Experiences}

The conceptual lens of intersectionality serves as a culturally nuanced framework through which faculty can better understand the experiences and thus support the success of URM students. Intersectionality underscores the interconnectedness of social identities and systems of social oppression and privilege [71]. This approach recognizes how multidimensional interconnections of social identities (e.g., race, gender, sexuality, social class) shape power relations on campus and perpetuate educational inequities in interactional ways [72]. As such, it is important to faculty as they build relationships with URM students to consider how various identities and related systems of oppression (e.g., racism, sexism, classism, nativism, heterosexism, etc.) are simultaneously experienced and how it shapes their experiences on campus. Indeed, a majority of URM students are women. Case and Lewis [73] offered strategies and experiences using intersectionality in the classroom to support students' learning and development and foster social justice orientation and activism.

\subsection{Decolonize the Curriculum and Classroom}

Contemporary scholars have emphasized the importance of decolonizing university curricula and de-centering pedagogy from a White racial frame. At a basic level, decolonizing the curriculum means including voices that have been historically marginalized in the discipline. It also means working actively against "epistemicide", or predatory discourse where different and non-dominant ways of knowing are devalued or appropri- 
ated into an acceptable shape [74]. Indeed, some question whether it is possible to truly decolonize the curriculum at universities that currently sit on the traditional homelands of indigenous peoples [75]. As such, faculty who function in systems rooted in oppression and colonialism need to be intentional about creating spaces and engaging discourse with the campus community that center voices and worldviews that are not exclusively or overwhelmingly male, White, and of European descent [76]. This is not just about replacing content in the curriculum; it is about deeply considering perspectives that have been historically marginalized and critically analyzing what is valued in the context of teaching and learning.

\subsection{Be Anti-Racist and Address Racial Bias in the Classroom}

Given the ways in which structural racism is perpetuated in higher education, there is a call for faculty to take a non-neutral stance of anti-racist pedagogy. Like decolonization, there is a critical questioning of the ways of knowing and how knowledge is created. Basque and Britto [77] described an anti-racist pedagogue as someone who "acts critically and with intention by facilitating dialogue, questioning personal values, deconstructing whiteness and assuming heterogeneity. Anti-racist educators seek to preserve and translate language so that cultural meanings are deconstructed, mutually understood and accessible to all" (p. 7). According to the authors, faculty can bring these values to bear in several ways. First, anti-racist pedagogy means engaging the campus community on issues of race and racism as well as ensuring campus policies are anti-racist. Second, it is important for faculty to reflect on who benefits from their current teaching practices and definitions of academic success. Faculty should be willing to evaluate and re-write the curriculum to be more inclusive. Finally, they argue that faculty can set the tone and create an empathic environment for having meaningful and sometimes discomforting conversations about race and racism. We further argue for the need to overcome colorblind ideologies in coursework that minimize the role of race and nativity in peoples' lives and in so doing deny related power dynamics and inequities [78]. Critical race theorists and educators emphasize the importance of racial awareness through experiential exercises weaved into the entire curriculum rather than a single lecture or class [79].

A discussion about what faculty can do to foster academic persistence among URM students would be remiss without a discussion of racism inside university classrooms. Research has documented the shift from overt forms of racism (openly expressed prejudice and discrimination) in contemporary times to more subtle forms of racism, often referred to as racial microaggressions [80]. Racial microaggressions are the modern-day, indirect, difficult to detect, and sometimes unintentional racial indignity, prejudice, mistreatment, or offense people of color experience [81]. Meta-analytic findings show the important links between racial microaggression and various adjustment outcomes [82]. Several qualitative studies have detailed URM students' experiences of racial microaggressions in faculty-student interactions. Therein, students report their concerns and perspectives being ignored in classrooms, their cultural experiences being distorted, omitted, or stereotyped in curricula, and professors maintaining negative assumptions about their academic abilities [8,83-85]. Moreover, enduring this differential treatment by faculty based on race has been shown to create a "cumulative burden" for URM students, characterized by feelings of self-doubt, isolation, and excess stress, that may impede their academic success [84,85]. It is important for faculty to address race and racism head-on in the classroom, not discriminate, and empower students to reflect on their own biases and take value-based steps in building a more inclusive campus and society.

\subsection{Incorporate Issues of Culture and Diversity into Course Content, Even in STEM Fields}

Recent studies suggest that not only does teaching style matter for URM student retention but potentially also the course content that professors choose. Curriculum that directly addresses culture and ethnicity may contribute to URM students' identity development [86], providing them something deeply valuable that they can take away 
from the course. Issues of culture and diversity tend to be addressed directly in social science and humanities courses but overlooked in science, technology, engineering, and math (STEM). At the same time, URM students are especially underrepresented in STEM majors [87]. Though many URM students start college as STEM majors, they are much more likely than their White counterparts to leave STEM and move to humanities and social science departments, perhaps due to the lack of cultural content in STEM courses [32].

Though this hypothesis requires further empirical testing, STEM professors need to engage in anti-racist teaching and training by incorporating the perspectives of people and scholars of color as this approach has proven valuable for engaging URM students in the humanities and social sciences [69]. It may not immediately be apparent how to bring a cultural perspective to a subject such as calculus or chemistry, but some possibilities include: discussing the contributions of important URM scholars in the field, outlining the cultural context of the research and theories being discussed in class, and acknowledging other systems of understanding besides the Western scientific method [26]. For instance, math and science instructors can discuss the ways in which measurement and "objectivity" have historically been used to establish and maintain systems of power [88]. The history of science abounds with examples, such as Blumenbach's five-race hierarchy, created by "objective" (i.e., cranial measurements) examination of human skulls. Based on these examinations, Blumenbach placed Caucasians at the top of the five-race hierarchy and suggested that the races that followed (Americans and Malays, then Mongolians and Ethiopians) were a result of degeneration and exposure to the environment [89]. Acknowledging and processing these historical and cultural underpinnings of supposedly culture-free subjects brings uncomfortable truths out into the open for examination and reveals some of the complex histories that are all too often erased from traditional Eurocentric curricula [90]. Instructors who are able to address these topics with sensitivity and humility may open the door to more impactful relationships with all students and particularly URM students who look to their courses for information and discussion of ethnic and cultural issues.

\subsection{Seek Opportunities to Further Personal Awareness and Knowledge on Issues of Diversity, Equity, and Inclusion}

The aforementioned recommendations are some of the ways faculty can create counterspaces that challenge prejudiced notions of URM students and promote their academic and social wellbeing. In addition, faculty should work to develop greater self-awareness of biases and stereotypes they may hold about URM students and how it might impact their instruction and the academic experiences of students of color. They should also seek training opportunities to develop pedagogical competencies intended to eliminate racial bias in their classrooms and to be actively anti-racist in their classrooms.

There is increasing recognition of the gap between what faculty learn in their graduate programs, which often emphasize research and expert knowledge, and the pedagogical knowledge and skills needed to meet the needs of diverse students. Faculty should seek continuing education on general teaching strategies and skills as well as those specifically helpful for diverse learners. Growing evidence suggests that URM students may perceive critical feedback from faculty differently than their White counterparts. Data from randomized controlled trials show the URM students, who may already be aware of negative cultural stereotypes about their ability, respond better to "wise feedback", wherein critical feedback is accompanied by an acknowledgment of high standards and expressed confidence in the student's ability to meet those standards [91]. Faculty development training should also address interpersonal attending skills (e.g., expressing empathy, actively listening, validation). Indeed, growing research shows the potential value of faculty, particularly faculty of color, as therapeutic agents for fostering wellbeing among URM students [92]. In addition to developing their own multicultural competence and inclusive pedagogy, faculty play a critical role in the education of students at large on how to understand issues of diversity and in so doing fostering critical thinking and emotional intelligence; there is a growing literature with practical strategies [93]. 


\section{Student Affairs and Academic Support: Considerations and Action Points for Staff}

Like faculty, student affairs and academic support professionals in higher education can be instrumental in fostering a sense of alignment between students and their campus environments. Specifically, past research has revealed significant ethnic-racial group differences in campus perceptions and experiences that merit the attention and intervention efforts by student support professionals. Student affairs professionals can play a critical role in the task of building diverse and inclusive campus communities. As liaisons between students and college administration, student support professionals can play a vital role in the psychosocial development of college students and often serve as the conduit for their college success.

\subsection{Track and Address Incidents of Racial Discrimination on Campus}

Professional staff serving diverse students need to be aware of the prevalence of incidents of racial discrimination and prejudice on campus, some of which have garnered media attention in recent years. URM students have long reported experiences of unfair treatment, pressure to conform/resist stereotypes, marginalization, criminalization, and being othered [41,94-96]. Intuitively, if students perceive their campus environment as hostile or unsafe, they are less likely to perceive congruence between who they are and their environment.

Available data support the assumption that continuous hostile race-ethnicity-related experiences and perceptions have important negative consequences for psychological wellbeing and academic adjustment, achievement, and commitment [97-101]. Importantly, it also underscores the dire need to cultivate educational communities that not only promote intellectual pursuits but also provide nurturing spaces where cultural diversity is respected and inclusivity is emphasized. Researchers have cautioned against the tendency for institutional actors to minimize racially biased incidents as "small and accidental slights," an invalidation that may have negative mental consequences for URM students [95]. As such, student affairs professionals should take complaints seriously and enhance campus bias reporting and tracking systems to be more nuanced in categorizing campus incidents by racial content and symbols to track trends over time (e.g., against Asian students during the COVID-19 pandemic [102]).

\subsection{Offer Outreach and Programming to Encourage Inclusivity and Educate the Campus Community}

There is an increased need for intercultural competence for support staff, including an awareness of the unique developmental, cultural, and social justice issues faced by URM students $[103,104]$. In addition to their own work towards intercultural competence, student support professionals should provide consultation and offer outreach programming to students, faculty, and other staff meant to increase awareness of role of race and racism in society broadly and specifically race-related experiences on campus, including the occurrence of racially biased incidents. Such programming should underscore the importance of an inclusive campus community, commitment to accountability, and the ongoing work to eliminate systems of oppression on campus and beyond. Scholars have highlighted the value of campus-wide and well-publicized anti-racism, allyship, and bystander trainings [105].

\subsection{Be Proactive in Creating Programming and Not Unduly Relying on URM Student Organizations}

We argue that college persistence is situated at this intersection of personal and academic; here the accountability of student affairs professionals for the retention of URM students becomes quite apparent. Research suggests that URM students sometimes feel alienated on college campuses, which likely contributes to their disproportionate attrition rate [106]. Although many colleges have diversity-focused student organizations that have been shown to facilitate social connectedness among students of color [107], relying solely 
on these groups for increasing feelings of belongingness places an undue burden on URM students to seek them out. As a result, it is imperative for student support professionals to be proactive in their efforts to create inclusive and culturally affirming campus-wide programming (i.e., beyond those sponsored by diversity-focused student organizations). Such programming would be beneficial to both URM students and their White counterparts because students now live and will eventually work in an increasingly interdependent global society, where becoming more educated about cultural diversity would likely be personally and professionally advantageous. Indeed, student affairs professionals can communicate that exposure to differences can be enriching and often leads to flexibility in thought and action [94].

\subsection{Provide Support to URM Students through Culturally Sensitive Counseling and Outreach}

It is important that attention is not only paid to educating on racism or reducing incidents of bias on campus but also to supporting those who may be targets whether directly or vicariously. This is particularly relevant for college mental health counselors as past research shows that mental health concerns can be exacerbated or precipitated by race-related stress [108,109]. It is important that counselors are aware of the unique needs of URM students across and within racial and ethnic groups. Outreach needs to be front and center of this work as it is well documented that URM students underutilize mental health services more than their White counterparts, even when reporting higher distress [110-112]. Outreach efforts could include workshops that provide information about available services that seek to provide inclusive and actively anti-racist counseling and demystify counseling. It is also important to go where URM students are. Empirical findings point to the value of counselor-in-residence programs on campus (i.e., positioning a mental health provider in non-clinical settings such as cultural centers and student unions), showing links to reducing mental health stigma, increasing psychological helpseeking behaviors, and improving therapeutic alliance between URM students and their mental health providers $[113,114]$. The COVID-19 pandemic and racial uprising have been linked to disproportionate mental health concerns for URM students [115]. Moreover, communities of color are also more severely impacted by COVID-19 and by the negative economic effects of the pandemic [105]. All of which make the need for culturally sensitive, quality, and affordable mental health services even more urgent.

\subsection{Plan and Execute Campus Interventions and Programming to Increase URM Retention}

Growing literature provides evidence that students from underrepresented groups are responsive to campus interventions that authenticate their sense of self and history. One randomized controlled study showed that incoming first-generation college students who attended a one-hour panel where panelists shared real-life stories that emphasized how their different backgrounds mattered in college fared better than students who attended a standard panel about college readiness [116]. In particular, students in the experiential group had higher end-of-year grade point averages, were more likely to seek campus resources, and reported higher psychological functioning and campus engagement. This work highlights the importance of programming for all students (that is, not just URM) that explores the importance of cultural identity in people's lives and the relationship between life narratives and academic experiences. Indeed, the authors write, "although the intervention targeted first-generation college students, its main message-people's different backgrounds matter, and people with different backgrounds can be successfulcan and should be leveraged to foster more inclusive and equitable schools, workplaces, and communities" (p. 9).

\subsection{Assist URM Students with Identifying Courses across Disciplines That Focus on Issues of Diversity}

As previously discussed, it is important for instructors to integrate cultural issues within coursework to retain URM students. By incorporating cultural issues into coursework, instructors and professors give space for students to form connections between the 
self and the topic. Multicultural content, however, is often absent in the core curriculum of particular majors. Academic advisors and other student support personnel are instrumental in addressing this deficiency as they can assist in identifying courses across disciplines that will provide students with opportunities to engage in critical dialogues on diversity. This also means that professors, who are generally not trained in culturally sensitive and culturally adaptive instruction, should be offered opportunities on how to incorporate identity-relevant content for URM students.

In addition to contributing to the academic experience of URM students [117,118], recommending culturally based courses has also been found to promote cross-cultural interactions, thus, benefitting the campus as a whole [119,120]. Advising itself is integral to student persistence. For instance, Metzner's [121] study of over 1000 college freshmen found that high-quality advising was related to academic performance, greater satisfaction, and a decrease in students' intentions to leave college early. More specifically, however, advisors can help direct students to instructors whose course content provides opportunities for URM students to connect to the material in personally and culturally meaningful ways.

\section{Institutional Governance: Considerations and Action Points for Campus Administrators}

Campus administrators arguably have the most power to make structural changes that will facilitate the retention of URM students as overseers of the institution, departments, personnel, strategic plans, budgets, facilities, curricula, and much more. While the titles vary by context (e.g., president, dean, director, chair, etc.), in this section, we address campus actors that lead and direct operations of a higher education institution. We want to begin by naming the cyclical problem - the problem of retention of URM students is intrinsically related to the lack of URM faculty and staff members that in turn reduces the possible number of students of color at the doctoral-level and as professionals in higher educations. Rather than seeing this cycle as a disadvantage, we believe that this cycle suggests a structure which administrators should draw on when seeking to support retention of URM students through increased hiring of faculty of color as well as student support professionals of color. If these problems are fundamentally two parts of the same defective system, their solution(s) should be as well.

\subsection{Institute Programming and Initiatives to Recruit and Retain URM Faculty and Staff}

The information presented in the proceeding sections of this paper suggests that the implications of the "leaky academic pipeline" in higher education go far beyond the time during which URMs are pursuing an undergraduate education. This leaky academic pipeline is the singular channel by which individuals can enter academia as faculty, and thus one result of low retention of URM students is a dearth of faculty of color. Of all full-time faculty in degree-granting postsecondary institutions in fall 2018,75\% were White, $12 \%$ were Asian/Pacific Islander, $6 \%$ were Black, $6 \%$ were Hispanic, and less than $1 \%$ were American Indian/Alaska Native [122]. The low numbers of faculty of color in higher education institutions are far removed from the country's demographic profile. A major priority for administration should be hiring a more diverse faculty who are supported upon arrival and nurtured to thrive. Examining federal data from all degree-granting postsecondary institutions, Stout and colleagues found positive association between faculty diversity and graduation rates for all URM students [123].

The benefits that faculty and staff of color bring to departments and universities are beyond enumeration, though it is important to note that it is not only URM students who benefit from their presence [124,125]. For example, faculty of color increase involvement in new areas and methods of research as well as employing more varied teaching styles [126]. Additionally, greater faculty and staff of color decreases the "burden of representation" placed on existing URM faculty and staff members, requiring them to be the representative voice of their groups [127]. Thus, the low numbers of faculty and staff of color have far-reaching implications. Without faculty and staff of color, departments also lack the role models, mentors, and quite often, interest in research on diverse populations that 
are integral in recruiting and retaining URM students $[128,129]$. Research has found that a match between mentor and mentee ethnicity has a positive impact on mentoring outcomes [130], and we suggest that one of the important mentoring outcomes may be an increased congruence between students and their academic environments.

Research is showing the promise of cluster or cohort hiring of faculty and staff for administrators seeking to diversify their faculty—where multiple candidates are hired as a group based on shared interests or experiences across different fields [131]. As we noted earlier, part of the challenge of recruiting and retaining students, staff, and faculty of color is due to the lack of other students, staff, and faculty of color, which leaves them at risk for feeling isolated and demoralized [132].By providing faculty and staff with a cohort of similarly placed individuals, available research suggests institutions can help them build a community of support and increase belongingness. Cluster hiring has been linked with increased faculty diversity and retention across several institutions [131,133]. Similar to students, once on campus, it is important that URM faculty and staff are well supported as they transition to their new role and navigate the written and unwritten rules of academia $[134,135]$. Given that URM faculty and staff may not have access to the same professional networks as their counterparts, administrators should institute voluntary mentoring programs to help with this transition as well as ongoing development as URM faculty and staff progress through major career milestones [132,136].

While much of the available literature focuses more on faculty than student support staff in academia, we want to make a special case for the investment in recruiting and retaining staff of color. Previous research has documented both the need for and benefits of staff of color mentoring URM students. For example, Luedke [137] found that URM students perceive that White staff tend to focus exclusively on their academic experiences, neglecting their cultural backgrounds. Whereas the students in the study reported staff of color were more likely to value their backgrounds and prior capital; as such, the students felt that they could be their authentic selves, gain support, and further develop social capital. The author emphasizes the importance of treating URM students as persons first and students second, recognizing and celebrating students' rich cultural backgrounds and facilitating spaces where they can share their prior capital while acquiring additional forms of capital. Staff play a unique role in connecting URM students with both personal and instrumental resources and may be better equipped to reach students who may be less likely to reach out to faculty and administration.

\subsection{Address the Fragmentation of Initiatives Focused on Diversity, Equity, and Inclusion}

While many colleges and universities in the United States now have diversity initiatives and programs for both hiring and admitting individuals of color, data suggest these initiatives are limited in their effectiveness [138]. For example, executive-level diversity officers seem to have little impact in making faculty more diverse [139]. We suggest that perhaps one barrier to the resolution of these problems is the structuring of their solutions within academia. At one of our institutions, for instance, the Office for Equity and Diversity houses two programs aimed to increase the diversity of full-time faculty hires and postdoctoral fellows as well as the Office for Diversity in Graduate Education, while recruitment of multicultural students is housed in the Office of Admissions. Furthermore, student retention strategies are housed under a variety of offices including the Office of Undergraduate Education and Office of Student Services. Finally, the recruitment of staff of color is facilitated by human resources, and their retention is the focus of a new campus initiative. Taken together, the solutions pipeline has been fundamentally fragmented, all but preventing the easy flow of solutions between undergraduate and graduate admissions, faculty hiring and recruitment, and student retention. We suggest that this fragmentation of solutions occurs at institutions all over the country and that it is the joining of these types of initiatives and programs across offices and the rethinking of these issues as part of the same whole that can lead institutions on the path to solving the cyclical problem of student retention. 


\subsection{Engage in Power Sharing}

Contemporary scholars have held college leaders to task for incorrectly assuming that increasing support resources to students and faculty is the only solution to persistent systemic racism in higher education [140]. We echo their recommendations which call for administrators and the entire campus community to be educated on historical and current manifestations of systemic racism and for there to be power sharing (or restructuring) across racial lines including at the highest level of campus leadership.

\subsection{Address Bias in Evaluations of URM Faculty and Staff}

It is critical for administrators to review current hiring and promotion policies and ensure they are not only anti-discriminatory but, specifically, anti-racist. These decisions should be made in partnership with URM faculty, staff, and students. Drawing from 118 interviews of faculty of color, Settles and colleagues described the paradox of URM faculty feeling both highly visible (e.g., heightened scrutiny) and yet invisible (e.g., work undervalued, marginalized) within the academy [141]. As such, institutions need to be careful to not position URM faculty token representatives of diversity and take serious steps in altering the incentive structures that perpetuate biases in merit review. Scholars have highlighted the concept of epistemic exclusion, where certain research topics and methods are devalued (e.g., research that focused on the lived experience of minoritized communities or publications in cultural journals; [141]). Scholars have suggested that this is one of the many ways URMs are gatekept out of academia [142,143]. At the same time, administrators need to be careful of the prejudice of low expectations in offering support to URM faculty. Although we are not aware of any research concerning low expectations of URM faculty, there is a robust literature on low expectations of URMs, especially Black students, throughout K-12 and university education [144,145], and that low expectations have negative impacts on later educational advancement [146]. Accordingly, it is critical that administrators understand the context and barriers to the performance of URM faculty while also maintaining high expectations for the quality of their work.

Moreover, there is growing empirical research showing that student evaluations of teaching (SET) are biased against women and URM faculty $[147,148]$. The available literature supports the reform of measures of teaching effectiveness; as Chavez and Mitchell [149] noted "in their current form, SETs might constitute another 'weep hole' for women and minorities in academic career pipelines that structurally contribute to higher attrition and lower achievement" (p. 273). As such, we strongly recommend a culture of transparency and consistency for academic reviews, emphasizing a nuanced understanding of entrenched inequities that may interact with how URM faculty are being assessed [132].

\subsection{Allocate Specific Funds for Diversity, Equity, and Inclusion Initiative on Campus}

We offer our recommendation of restructuring hiring, recruitment, and retention strategies for administrators, as well as our previous suggestions regarding course content and campus climate with an understanding that these changes require the redirection of resources by already financially strained campuses. Therefore, a discussion of the action points for university governance cannot be completed without some mention of funding. Universities must recognize the absolute necessity of addressing the problem of retention of URM students through the redirection of finances to changes that increase belongingness for URM students. As diversity in this country increases and college campuses tout their "multicultural" programming, it is essential that financial resources are directed towards the deeper structural changes that we suggest could have a lasting impact on both the retention of URM students and to the campus climate as a whole. Perhaps the first step is for universities to recognize what they stand to gain from an investment in retention of URM students, not only financially through greater student numbers, but also through increased innovation in research, methods of teaching, and community involvement [22-24]. To be successful, there also has to be a concomitant investment in faculty and staff of color. 


\section{Conclusions}

Research in psychology has historically focused on individual-level factors implicated in academic adjustment [148]. Among investigations that examine the variables that predict academic success, for example, much more is known about the roles of individual factors (e.g., attitudes, traits, abilities) than is known about contextual factors (e.g., campus climate, academic curriculum). Given the suggestion that college adjustment and retention are predicated on positive interactions between the self and the environment, there is more to gain from a better understanding of the person-environment transactions that give rise to academic wellbeing and belonging. We argue that it is faculty, student support staff, and university governance that have the power to make the content and structural changes that have the potential to foster belongingness in URM students. We also recognize that while some students may find that involvement in cultural activities related to their ethnic background increases their feelings of belongingness, this is not the only pathway to person-environment fit. We suggest that particularly in emerging adulthood when exploration of the self plays a central role, colleges can, through strategic and carefully planned changes, create spaces in which URM students can flourish.

By placing the impetus for change on the faculty, student support staff, and institution administrators, we see the potential for a greater and longer-lasting impact on the academic pipeline for URM students. The recognition that each partner in the person-environment context of academia plays a role in increasing retention and satisfaction for students of color may help universities to address these issues more creatively and effectively. That said, we are aware of the limitations of top-down solutions. All the recommendations above should be done in the spirit of empowering students to make the campus theirs. It is important to include them in shared governance and decision making. For example, students' perspectives can be empowered by including them and allowing them to vote in faculty hiring committees, curricular reform committees, and admission committees. That way, they too can actively transform their environments. Finally, we focus on retaining students rather than recruiting students in this paper, though we acknowledge that retention of URM students is likely closely linked to their pathway to college. Future work should consider how efforts to attract and retain students can be integrated and offer recommendations on developing and implementing comprehensive plans for increasing the enrollment and persistence of students from diverse backgrounds. While our discussion as a whole has focused on the particularities of educational inequities in the U.S. context, marginalization and inequalities based on social identity are not unique to the U.S. We hope scholars outside the U.S. will find relevance in improving education outcomes for minoritized populations in their countries.

Author Contributions: Conceptualization, A.A.A., L.L.M., S.C.N., J.F., L.H.M.P., J.M.C. and M.S.; Writing-original draft, A.A.A., L.L.M. and S.C.N.; Writing-review \& editing, A.A.A., L.L.M., S.C.N., J.F., L.H.M.P., J.M.C. and M.S. All authors have read and agreed to the published version of the manuscript.

Funding: This research received no external funding.

Data Availability Statement: Not applicable.

Conflicts of Interest: The authors declare no conflict of interest.

\section{References}

1. Baum, S.; Payea, K. Education Pays, 2004: The Benefits of Higher Education for Individuals and Society; College Board: New York, NY, USA, 2005.

2. Darling-Hammond, L. Unequal opportunity: Race and education. Brook. Rev. 1998, 16, 28-32. [CrossRef]

3. Winkle-Wagner, R.; Locks, A. Diversity and Inclusion on Campus: Supporting Racially and Ethnically Underrepresented Students; Routledge: London, UK, 2013.

4. Hartocollis, A. After a Year of Turmoil, Elite Universities Welcome More Diverse Freshman Classes. Available online: https: //www.nytimes.com/2021/04/17/us/minority-acceptance-ivy-league-cornell.html (accessed on 20 May 2021). 
5. Cahalan, M.W.; Perna, L.W.; Addison, M.; Murray, C.; Patel, P.R.; Jiang, N. Indicators of Higher Education Equity in the United States: 2020 Historical Trend Report; Pell Institute for the Study of Opportunity in Higher Education: Washington, DC, USA, 2020.

6. Jones, W.A. The Persistence of Students of Color. In Handbook of Strategic Enrollment Management; Hossler, D., Bontrager, B., Eds.; John Wiley \& Sons: Hoboken, NJ, USA, 2014.

7. Sullivan, L.; Meschede, T.; Dietrich, L.; Shapiro, T. The Racial Wealth Gap Increases Fourfold; Institute on Assets and Social Policy, Brandeis University: Waltham, MA, USA, 2015.

8. Bailey, K.A. Racism within the Canadian university: Indigenous students' experiences. Ethn. Racial Stud. 2016, 39, 1261-1279. [CrossRef]

9. Turk-Bicakci, L.; Berger, A.; Haxton, C. The Nonacademic Careers of STEM PhD Holders. 2014. Available online: http:/ /www.air. org/sites/default/files/downloads/report/STEM\%20nonacademic\%20careers\%20April14.pdf (accessed on 20 May 2021).

10. Del Toro, J.; Hughes, D. Trajectories of Discrimination across the College Years: Associations with Academic, Psychological, and Physical Adjustment Outcomes. J. Youth Adolesc. 2020, 49, 772-789. [CrossRef] [PubMed]

11. Meeuwisse, M.; Severiens, S.E.; Born, M.P. Learning environment, interaction, sense of belonging and study success in ethnically diverse student groups. Res. High. Educ. 2010, 51, 528-545. [CrossRef]

12. Wolf, D.A.P.S.; Taylor, F.; Maguin, E.; BlackDeer, A.A. You are college material—You belong: An underrepresented minority student retention intervention without deception. J. Coll. Stud. Retent. Res. Theory Pract. 2019, 1-16. [CrossRef]

13. Permzadian, V.; Credé, M. Do First-Year Seminars Improve College Grades and Retention? A Quantitative Review of Their Overall Effectiveness and an Examination of Moderators of Effectiveness. Rev. Educ. Res. 2015, 86, 277-316. [CrossRef]

14. Tinto, V. Student Retention and Graduation: Facing the Truth, Living with the Consequences. Occasional Paper 1. 2004. Available online: https: / / files.eric.ed.gov/fulltext/ED519709.pdf (accessed on 20 May 2021).

15. Caplan, R.D. Person-environment fit theory and organizations: Commensurate dimensions, time perspectives, and mechanisms. J. Vocat. Behav. 1987, 3, 248-267. [CrossRef]

16. Porter, S.R.; Umbach, P.D. College major choice: An analysis of person-environment fit. Res. High. Educ. 2006, 4, 429-449. [CrossRef]

17. de Brey, C.; Musu, L.; McFarland, J.; Wilkinson-Flicker, S.; Diliberti, M.; Zhang, A.; Branstetter, C.; Wang, X. Status and Trends in the Education of Racial and Ethnic Groups 2018 (NCES 2019-038); U.S. Department of Education: Washington, DC, USA, 2019. Available online: https:/ / nces.ed.gov/pubsearch (accessed on 20 May 2021).

18. Makuakane-Drechsel, T.; Hagedorn, L.S. Correlates of retention among Asian Pacific Americans in community colleges: The case for Hawaiian students. Community Coll. J. Res. Pract. 2000, 24, 639-655. [CrossRef]

19. Museus, S.D.; Kiang, P.N. Deconstructing the model minority myth and how it contributes to the invisible minority reality in higher education research. New Dir. Inst. Res. 2009, 142, 5-15. [CrossRef]

20. Whistle, W. Ripple Effect: The Cost of the College Dropout Rate. 2019. Available online: https://www.thirdway.org/report/ ripple-effect-the-cost-of-the-college-dropout-rate9 (accessed on 20 May 2021).

21. Johnson, N. The Institutional Costs of Student Attrition. Research Paper. 2012. Available online: https://files.eric.ed.gov/ fulltext/ED536126.pdf (accessed on 20 May 2021).

22. Page, S.E. The Difference: How the Power of Diversity Creates Better Groups, Firms, Schools, and Societies; Princeton University Press: Princeton, NJ, USA, 2007.

23. Williams, K.Y.; O'Reilly, C.A. Demography and diversity in organizations: A review of 40 Years of research. In Research in Organizational Behavior; Staw, B.M., Cummings, L.L., Eds.; JAI Press: Greenwich, CT, USA, 1998; pp. 77-140.

24. Beck, R.J. The Greatest Good for the Greatest Number: An Experimental Study of the Effects of Racial and Ethnic Diversity on Liberal Arts College Discussions. 2009. Available online: https:/ / citeseerx.ist.psu.edu/viewdoc/download?doi=10.1.1.1043.5258 \&rep=rep1\&type $=$ pdf (accessed on 20 May 2021).

25. Freeman, R.B.; Huang, W. Collaborating with People Like Me: Ethnic Co-Authorship within the US (Working Paper No. 19905). 2014. Available online: http:/ / www.nber.org/papers/w19905 (accessed on 20 May 2021).

26. Syed, M.; Azmitia, M.; Cooper, C.R. Identity and academic success among under-represented ethnic minorities: An interdisciplinary review and integration. J. Soc. Issues 2011, 6, 442-468. [CrossRef]

27. Tinto, V. Research and practice of student retention: What next? J. Coll. Stud. Retent. Res. Theory Pract. 2006, 8, 1-19. [CrossRef]

28. Tinto, V. Completing College: Rethinking Institutional Action; University of Chicago Press: Chicago, IL, USA, 2012.

29. Fish, J.; Syed, M. Native Americans in higher education: An ecological systems perspective. J. Coll. Stud. Dev. 2018, 59, 387-403. [CrossRef]

30. Tinto, V. Leaving College: Rethinking the Causes and Cures of Student Attrition; University of Chicago Press: Chicago, IL, USA, 1993; Volume 2.

31. Stovall, M. Using success courses for promoting persistence and completion. New Dir. Community Coll. 2000, 112, 45-54. [CrossRef]

32. Syed, M. Developing an integrated self: Academic and ethnic identities among ethnically-diverse college students. Dev. Psychol. 2010, 46, 1590-1604. [CrossRef]

33. Walker, L.H.M.; Syed, M. Integrating identities: Ethnic and academic identities among diverse college students. Teach. Coll. Rec. 2013, 115, 1-24. 
34. Westrick, P.A.; Le, H.; Robbins, S.B.; Radunzel, J.M.; Schmidt, F.L. College performance and retention: A meta-analysis of the predictive validities of ACT ${ }^{\circledR}$ scores, high school grades, and SES. Educ. Assess. 2015, 20, 23-45. [CrossRef]

35. Guay, F.; Ratelle, C.F.; Roy, A.; Litalien, D. Academic self-concept, autonomous academic motivation, and academic achievement: Mediating and additive effects. Learn. Individ. Differ. 2010, 20, 644-653. [CrossRef]

36. Ryland, E.B.; Riordan, R.J.; Brack, G. Selected characteristics of high-risk students and their enrollment persistence. J. Coll. Stud. Dev. 1994, 35, 54-58.

37. DeBerard, M.S.; Spielmans, G.I.; Julka, D.C. Predictors of academic achievement and retention among college freshmen: A longitudinal study. Coll. Stud. J. 2004, 38, 66-80.

38. Dynarski, S.M. Does aid matter? Measuring the effect of student aid on college attendance and completion. Am. Econ. Rev. 2003, 93, 279-288. [CrossRef]

39. Museus, S.D. Generating Ethnic Minority Student Success (GEMS): A qualitative analysis of high-performing institutions. J. Divers. High. Educ. 2011, 4, 147-162. [CrossRef]

40. Campbell, T.A.; Campbell, D.E. Faculty/student mentor program: Effects on academic performance and retention. Res. High. Educ. 1997, 38, 727-742. [CrossRef]

41. Habley, W.R.; McClanahan, R. What Works in Student Retention? Four Year Public Colleges; ACT: Iowa City, IA, USA, 2004.

42. Grier-Reed, T.; Maples, A.; Williams-Wengerd, A.; McGee, D. The Emergence of Racialized Labor and Racial Battle Fatigue in the African American Student Network (AFAM). JCSCORE 2020, 6, 94-135. [CrossRef]

43. Smith, W.A. Racial Battle Fatigue in Higher Education: Exposing the Myth of Post-Racial America; Rowman \& Littlefield: Lanham, MD, USA, 2014.

44. Franklin, J. Racial microaggressions, racial battle fatigue, and racism-related stress in higher education. J. Stud. Aff. N. Y. Univ. 2016, 12, 44-55.

45. Bauman, K.; Cranney, S. School Enrollment in the United States: 2018. Population Characteristics. Current Population Reports; US Census Bureau: Suitland-Silver Hill, MD, USA, 2020.

46. Arnett, J.J. Emerging adulthood: A theory of development from the late teens through the twenties. Am. Psychol. 2000, 55, 469-480. [CrossRef]

47. Wood, D.; Crapnell, T.; Lau, L.; Bennett, A.; Lotstein, D.; Ferris, M.; Kuo, A. Emerging adulthood as a critical stage in the life course. In Handbook of Life Course Health Development; Halfon, N., Forrest, C., Lerner, L., Faustman, E., Eds.; Springer International Publishing: Berlin, Germany, 2018; pp. 123-143.

48. Arnett, J.J. Emerging Adulthood: The Winding Road from the Late Teens through the Twenties; Oxford University Press: New York, NY, USA, 2004.

49. Lefkowitz, E.S.; Gillen, M.M. "Sex Is Just a Normal Part of Life": Sexuality in Emerging Adulthood. In Coming of Age in the 21st Century: The Lives and Contexts of Emerging Adults; Arnett, J., Tanner, J., Eds.; American Psychological Association: Washington, DC, USA, 2006; pp. 235-255.

50. Phinney, J. Ethnic identity exploration in emerging adulthood. In Coming of Age in the 21st Century: The Lives and Contexts of Emerging Adults; Arnett, J., Tanner, J., Eds.; American Psychological Association: Washington, DC, USA, 2006 ; pp. 117-134.

51. Syed, M.; Mitchell, L.L. Race, ethnicity, and emerging adulthood: Retrospect and prospects. Emerg. Adulthood 2013, 1, 83-95. [CrossRef]

52. Grier-Reed, T.; Ajayi, A.; Wilson, R.; Cotton, D. Foundational curriculum for the African American Student Network: Synthesis of discussion topics and themes. J. Adolesc. Fam. Health 2020, 11, 1-30.

53. Brock, T. Young adults and higher education: Barriers and breakthroughs to success. Future Child. 2010, 20, 109-132. [CrossRef]

54. McAdams, D.P.; Guo, J. How shall I live? Constructing a life story in the college years. New Dir. High. Educ. 2014, 166, 15-23. [CrossRef]

55. Simplicio, J.S.C. Shared governance: An analysis of power on the modern university campus from the perspective of an administrator. Education 2006, 126, 763-768.

56. Pascarella, E.T.; Terenzini, P.T. How College Affects Students; Jossey-Bass: San Francisco, CA, USA, 1991.

57. Arana, R.; Castañeda-Sound, C.; Blanchard, S.; Aguilar, T.E. Indicators of persistence for Hispanic undergraduate achievement: Toward an ecological model. J. Hisp. High. Educ. 2010, 10, 237-251. [CrossRef]

58. Lundberg, C.A.; Schreiner, L.A. Quality and frequency of student-faculty interaction as predictors of learning: An analysis by student race/ethnicity. J. Coll. Stud. Dev. 2004, 35, 217-223. [CrossRef]

59. Cole, D. Do interracial interactions matter? An examination of student-faculty contact and intellectual self-concept. J. High. Educ. 2007, 78, 249-281. [CrossRef]

60. Davis, J.E. College in black and white: Campus environment and academic achievement of African American males. J. Negro Educ. 1994, 63, 620-633. [CrossRef]

61. Hurtado, S. The institutional climate for talented Latino students. Res. High. Educ. 1994, 35, 21-41. [CrossRef]

62. Fries-Britt, S. Identity development of high-ability Black collegians. New Dir. Teach. Learn. 2000, 82, 55-65. [CrossRef]

63. Cokley, K. Perceived faculty encouragement and its influence on college students. J. Coll. Stud. Dev. 2000, 41, 348-352.

64. Rendón, L. Validating culturally diverse students: Toward a new model of learning and student development. Innov. High. Educ. 1994, 19, 33-52. [CrossRef] 
65. Cole, D. Constructive criticism: The role of student-faculty interactions on African American and Hispanic students' educational gains. J. Coll. Stud. Dev. 2008, 49, 587-605. [CrossRef]

66. O'Donnell, K.; Botelho, J.; Brown, J.; González, G.M.; Head, W. Undergraduate Research and Its Impact on Student Success for Underrepresented Students. New Dir. High. Educ. 2015, 169, 27-38. [CrossRef]

67. Nagda, B.A.; Gregerman, S.R.; Jonides, J.; Von Hippel, W.; Learner, J.S. Undergraduate student-faculty research partnerships affect student retention. Rev. High. Educ. 1998, 22, 55-72. [CrossRef]

68. Kinzie, J.; Gonyea, R.; Shoup, R.; Kuh, G.D. Promoting persistence and success of underrepresented students: Lessons for teaching and learning. New Dir. Teach. Learn. 2008, 115, 21-38. [CrossRef]

69. Museus, S.D.; Lâm, S.C.; Huang, C.; Kem, P.; Tan, K. Cultural integration in campus subcultures: Where the cultural, academic, and social spheres of college life collide. In Creating Campus Cultures: Fostering Success among Racially Diverse Student Populations; Museus, S.D., Jayakumar, U.M., Eds.; Routledge: New York, NY, USA, 2012; pp. 106-129.

70. Kricorian, K.; Seu, M.; Lopez, D.; Ureta, E.; Equils, O. Factors influencing participation of underrepresented students in STEM fields: Matched mentors and mindsets. Int. J. STEM Educ. 2020, 7, 1-9. [CrossRef]

71. Crenshaw, K. Race, gender, and sexual harassment. South. Calif. Law Rev. 1991, 65, 1467-1476.

72. Núñez, A.M. Advancing an intersectionality framework in higher education: Power and Latino postsecondary opportunity. In Higher Education: Handbook of Theory and Research; Paulsen, M., Ed.; Springer: Berlin, Germany, 2014; pp. 33-92.

73. Case, K.A.; Lewis, M.K. Teaching intersectional LGBT psychology: Reflections from historically Black and Hispanic-serving universities. Psychol. Sex. 2012, 3, 260-276. [CrossRef]

74. Bennett, K. Epistemicide! The tale of a predatory discourse. Translator 2007, 13, 151-169. [CrossRef]

75. Wysong, L. Does “Decolonization" Need Decolonizing? 2020. Available online: https://medium.com/hindsights/doesdecolonization-need-decolonizing-ad2023b74652 (accessed on 20 May 2021).

76. Charles, E. Decolonizing the curriculum. Insights 2019, 32, 24. [CrossRef]

77. Basque, K.M.; Britto, M. Anti-racist pedagogy: What does it look like in the classroom? Int. J. Home Econ. 2019, 12, 6-10. [CrossRef]

78. Diggles, K. Addressing racial awareness and color-blindness in higher education. New Dir. Teach. Learn. 2014, 140, 31-44. [CrossRef]

79. Hiraldo, P. The role of critical race theory in higher education. Vt. Connect. 2010, 31, 7.

80. Pierce, C. Stress analogs of racism and sexism: Terrorism, torture, and disaster. In Mental Heath, Racism, and Sexism; Willie, C., Rieker, P., Kramer, B., Brown, B., Eds.; University of Pittsburgh Press: Pittsburgh, PA, USA, 1995; pp. $277-293$.

81. Sue, D.W.; Capodilupo, C.M.; Torino, G.C.; Bucceri, J.M.; Holder, A.M.; Nadal, K.L.; Esquilin, M. Racial microaggressions in everyday life. Am. Psychol. 2007, 62, 271-286. [CrossRef] [PubMed]

82. Lui, P.P.; Quezada, L. Associations between microaggression and adjustment outcomes: A meta-analytic and narrative review. Psychol. Bull. 2019, 145, 45-78. [CrossRef] [PubMed]

83. McCabe, J. Racial and gender microaggressions on a predominantly-White campus: Experiences of Black, Latina/o and White undergraduates. Race Gend. Cl. 2009, 16, 133-151.

84. Solorzano, D.; Ceja, M.; Yosso, T. Critical race theory, racial microaggressions, and campus racial climate: The experiences of African American college students. J. Negro Educ. 2000, 69, 60-73.

85. Yosso, T.; Smith, W.; Ceja, M.; Solórzano, D. Critical race theory, racial microaggressions, and campus racial climate for Latina/o undergraduates. Harv. Educ. Rev. 2009, 79, 659-691. [CrossRef]

86. Santos, S.J.; Ortiz, A.M.; Morales, A.; Rosales, M. The relationship between campus diversity, students' ethnic identity and college adjustment: A qualitative study. Cult. Divers. Ethn. Minority Psychol. 2007, 13, 104-114. [CrossRef]

87. Chemers, M.M.; Zurbriggen, E.; Syed, M.; Goza, B.K.; Bearman, S. The role of efficacy and identity in science career commitment among underrepresented minority students. J. Soc. Issues 2011, 67, 469-491. [CrossRef]

88. Okun, T. Teaching about race and racism: The imperative of history. In Teaching Race and Anti-Racism in Contemporary America: Adding Context to Colorblindness; Haltinner, K., Ed.; Springer: New York, NY, USA, 2014; pp. 55-64. [CrossRef]

89. Blumenbach, J.F. De Generis Humani Varietate Native [On the Natural Variety of Humankind], 3rd ed.; Vandenhoek and Ruprecht: Göttingen, Germany, 1795.

90. Quaye, S.J.; Griffin, K.A.; Museus, S.D. Engaging students of color. In Student Engagement in Higher Education: Theoretical Perspectives and Practical Approaches for Diverse Populations; Quaye, S.J., Harper, S.R., Eds.; Routledge: New York, NY, USA, 2014; pp. 15-36.

91. Yeager, D.S.; Purdie-Vaughns, V.; Garcia, J.; Apfel, N.; Brzustoski, P.; Master, A.; Hessert, W.T.; William, M.E.; Cohen, G.L. Breaking the cycle of mistrust: Wise interventions to provide critical feedback across the racial divide. J. Exp. Psychol. Gen. 2014, 143, 804-824. [CrossRef] [PubMed]

92. Grier-Reed, T.; Ajayi, A.A. Incorporating humanistic values and techniques in a culturally responsive therapeutic intervention for African American college students. J. Humanist. Couns. 2019, 58, 17-33. [CrossRef]

93. Strasser, J.; Seplocha, H. How Can University Professors Help their Students Understand Issues of Diversity through Interpersonal \& Intrapersonal Intelligences? Multicult. Educ. 2015, 12, $20-24$.

94. Ancis, J.R.; Sedlacek, W.E.; Mohr, J.J. Student perceptions of campus cultural climate by race. J. Couns. Dev. 2000, 78, 180-185. [CrossRef] 
95. Garcia, G.A.; Johnston-Guerrero, M.P. Challenging the utility of a racial microaggressions framework through a systematic review of racially biased incidents on campus. J. Crit. Scholarsh. High. Educ. Stud. Aff. 2015, 2, 50-66.

96. Nora, A.; Cabrera, A.F. The role of perceptions of prejudice and discrimination on the adjustment of minority students to college. J. High. Educ. 1996, 67, 119-148. [CrossRef]

97. Ajayi, A.A.; Syed, M. Links between patterns of racial socialization and discrimination experiences and psychological adjustment: A cluster analysis. J. Adolesc. 2014, 37, 1011-1020. [CrossRef] [PubMed]

98. Alfaro, E.C.; Umaña-Taylor, A.J.; Gonzales-Backen, M.A.; Bámaca, M.Y.; Zeiders, K.H. Latino adolescents' academic success: The role of discrimination, academic motivation, and gender. J. Adolesc. 2009, 32, 941-962. [CrossRef]

99. Chavous, T.M.; Rivas-Drake, D.; Smalls, C.; Griffin, T.; Cogburn, C. Gender matters, too: The influences of school racial discrimination and racial identity on academic engagement outcomes among African American adolescents. Dev. Psychol. 2008, 44, 637-654. [CrossRef]

100. Hurtado, S.; Griffin, K.A.; Arellano, L.; Cuellar, M. Assessing the value of climate assessments: Progress and future directions. J. Divers. High. Educ. 2008, 1, 204-221. [CrossRef]

101. Neblett, E.W.; Philip, C.L.; Cogburn, C.D.; Sellers, R.M. African American adolescents' discrimination experiences and academic achievement: Racial socialization as a cultural compensatory and protective factor. J. Black Psychol. 2006, 32, 199-218. [CrossRef]

102. Gover, A.R.; Harper, S.B.; Langton, L. Anti-Asian hate crime during the COVID-19 pandemic: Exploring the reproduction of inequality. Am. J. Crim. Justice 2020, 45, 647-667. [CrossRef]

103. Johnson, C.V. A process-oriented group model for university students: A semi-structured approach. Int. J. Group Psychother. 2009, 59, 511-528. [CrossRef]

104. Phelps, R.E.; Taylor, J.D.; Gerard, P.A. Cultural mistrust, ethnic identity, racial identity, and self-esteem among ethnically diverse Black university students. J. Couns. Dev. 2001, 79, 209-216. [CrossRef]

105. Landertinger, L.C.; Greene, E.; Cooper, M.; Hopson, A. Emotional and Mental Health Support for Black Students: Responding to Racial Trauma and White Terror Amidst COVID-19. J. High. Educ. Manag. 2021, 36, 154-164.

106. Cheatham, H.E.; Berg-Cross, L. College student development: African Americans reconsidered. J. Coll. Stud. Psychother. 1993, 6, 167-191. [CrossRef]

107. Guiffrida, D.A. African American student organizations as agents of social integration. J. Coll. Stud. Dev. 2003, 44, 304-319. [CrossRef]

108. Bernard, D.L.; Lige, Q.M.; Willis, H.A.; Sosoo, E.E.; Neblett, E.W. Impostor phenomenon and mental health: The influence of racial discrimination and gender. J. Couns. Psychol. 2017, 64, 155-166. [CrossRef]

109. Pieterse, A.L.; Carter, R.T.; Evans, S.A.; Walter, R.A. An exploratory examination of the associations among racial and ethnic discrimination, racial climate, and trauma-related symptoms in a college student population. J. Couns. Psychol. 2010, 57, 255-263. [CrossRef]

110. Butler, S.K.; Evans, M.P.; Brooks, M.; Williams, C.R.; Bailey, D.F. Mentoring African American men during their postsecondary and graduate school experiences: Implications for the counseling profession. J. Couns. Dev. 2013, 91, 419-427. [CrossRef]

111. Cheng, H.L.; Kwan, K.L.; Sevig, T. Racial and ethnic minority college students' stigma associated with seeking psychological help: Examining psychocultural correlates. J. Couns. Psychol. 2013, 60, 98-111. [CrossRef]

112. Lipson, S.K.; Kern, A.; Eisenberg, D.; Breland-Noble, A.M. Mental health disparities among college students of color. J. Adolesc. Health 2018, 63, 348-356. [CrossRef]

113. Banks, B.M. University mental health outreach targeting students of color. J. Coll. Stud. Psychother. 2020, 34, 78-86. [CrossRef]

114. Boone, M.S.; Edwards, G.R.; Haltom, M.; Hill, J.S.; Liang, Y.; Mier, S.R.; Shropshire, S.Y.; Belizaire, L.S.; Kamp, L.C.; Murthi, M.; et al. Let's Talk: Getting Out of the Counseling Center to Serve Hard-to-Reach Students. J. Multicult. Couns. Dev. 2011, 39, 194-205. [CrossRef]

115. Trammell, J.P.; Joseph, N.T.; Harriger, J.A. Racial and ethnic minority disparities in COVID-19 related health, health beliefs and behaviors, and well-being among students. J. Am. Coll. Health 2021, 47, 777-780. [CrossRef]

116. Stephens, N.M.; Hamedani, M.G.; Destin, M. Closing the social-class achievement gap a difference-education intervention improves first-generation students' academic performance and all students' college transition. Psychol. Sci. 2014, 25, 943-953. [CrossRef]

117. Cheatham, H.E.; Phelps, C.E. Promoting the development of graduate students of color. New Dir. Stud. Serv. 1995, 72, 91-99. [CrossRef]

118. Maramba, D.C.; Velasquez, P. Influences of the campus experience on the ethnic identity development of students of color. Educ. Urban Soc. 2012, 44, 294-317. [CrossRef]

119. Maramba, D.C.; Museus, S.D. Examining the effects of campus climate, ethnic group cohesion, and cross-cultural interaction on Filipino American students' sense of belonging in college. J. Coll. Stud. Retent. Res. Theory Pract. 2012, 14, 495-522. [CrossRef]

120. Glass, C.R.; Westmont, C.M. Comparative effects of belongness on the academic success and cross-cultural interactions of domestic and international students. Int. J. Intercult. Relat. 2014, 38, 106-119. [CrossRef]

121. Metzner, B.S. Perceived quality of academic advising: The effect on freshman attrition. Am. Educ. Res. J. 1989, $26,422-442$. [CrossRef] 
122. U.S. Department of Education, National Center for Education Statistics. The Condition of Education 2020 (NCES 2020-144), Characteristics of Postsecondary Faculty. 2020. Available online: https://nces.ed.gov/programs/coe/indicator_csc.asp (accessed on 20 May 2021).

123. Stout, R.; Archie, C.; Cross, D.; Carman, C.A. The relationship between faculty diversity and graduation rates in higher education. Intercult. Educ. 2018, 29, 399-417. [CrossRef]

124. Cole, S.; Barber, E. Increasing Faculty Diversity: The Occupational Choices of Higher Achieving Minority Students; Harvard University Press: Cambridge, MA, USA, 2003.

125. Umbach, P.D. The contribution of faculty of color to undergraduate education. Res. High. Educ. 2006, 47, 317-345. [CrossRef]

126. Turner, C.S.V. New faces, new knowledge: As women and minorities join the faculty they bring intellectual diversity in pedagogy and in scholarship. Academe 2000, 86, 34-37. [CrossRef]

127. Gándara, P. Priming the Pump: Strategies for Increasing the Achievement of Underrepresented Minority Undergraduates; The College Board: New York, NY, USA, 1999.

128. Antonio, A.L. Faculty of color and scholarship transformed: New arguments for diversifying faculty. Divers. Dig. 2000, 3, 6-7.

129. Chapa, J. The educational pipeline and the future professoriate: Who will teach California's and the nation's Latino and African American college students. In Expanding Opportunity in Higher Education: Leveraging Promise; Gandera, P., Orfield, G., Horn, C.L., Eds.; State University of New York Press: Albany, NY, USA, 2006; pp. 243-264.

130. Blake-Beard, S.; Bayne, M.L.; Crosby, F.J.; Muller, C.B. Matching by race and gender in mentoring relationships: Keeping our eyes on the prize. J. Soc. Issues 2011, 67, 622-643. [CrossRef]

131. Sgoutas-Emch, S.; Baird, L.; Myers, P.; Camacho, M.; Lord, S. We're not all white men: Using a cohort/cluster approach to diversity STEM faculty hiring. Thought Action 2016, 32, 91-107.

132. Bhalla, N. Strategies to improve equity in faculty hiring. Mol. Biol. Cell 2019, 30, 2744-2749. [CrossRef] [PubMed]

133. Flaherty, C. Making Diversity Happen. 2017. Available online: https://www.insidehighered.com/news/2017/09/28/how-twoinstitutions-diversified-their-faculties-without-spending-big-or-setting (accessed on 20 May 2021).

134. Zambrana, R.E.; Ray, R.; Espino, M.M.; Castro, C.; Douthirt Cohen, B.; Eliason, J. “Don't leave us behind” The importance of mentoring for underrepresented minority faculty. Am. Educ. Res. J. 2015, 52, 40-72. [CrossRef]

135. Matthew, P.A. Written/Unwritten: Diversity and the Hidden Truths of Tenure; UNC Press Books: Chapel Hill, NC, USA, 2016.

136. Endo, R. Retaining and Supporting Faculty Who Are Black, Indigenous, and People of Color: The Promise of a Multi-Leveled Mentoring-Partnership Model. Multicult. Perspect. 2020, 22, 169-177. [CrossRef]

137. Luedke, C.L. Person first, student second: Staff and administrators of Color supporting Students of Color authentically in higher education. J. Coll. Stud. Dev. 2017, 58,37-52. [CrossRef]

138. Turner, C.S.V.; Gonzalez, J.C.; Wood, J.L. Faculty of color in academe: What 20 years of literature tells us. J. Divers. High. Educ. 2008, 1, 139-168. [CrossRef]

139. Bradley, S.W.; Garven, J.R.; Law, W.W.; West, J.E. The Impact of Chief Diversity Officers on Diverse Faculty Hiring (No. w24969); National Bureau of Economic Research: Cambridge, MA, USA, 2018; Available online: https://www.nber.org/papers/w24969 (accessed on 20 May 2021).

140. Ash, A.N.; Hill, R.; Risdon, S.; Jun, A. Anti-racism in higher education: A model for change. Race Pedagog. J. Teach. Learn. Justice 2020, 4, 1-35.

141. Settles, I.H.; Buchanan, N.T.; Dotson, K. Scrutinized but not recognized:(In) visibility and hypervisibility experiences of faculty of color. J. Vocat. Behav. 2019, 113, 62-74. [CrossRef]

142. Dotson, K. Conceptualizing epistemic oppression. Soc. Epistemol. 2014, 28, 115-138. [CrossRef]

143. Syed, M.; Santos, C.; Yoo, H.C.; Juang, L.P. Invisibility of racial/ethnic minorities in developmental science: Implications for research and institutional practices. Am. Psychol. 2018, 73, 812-826. [CrossRef]

144. Gershenson, S.; Holt, S.B.; Papageorge, N.W. Who believes in me? The effect of student-teacher demographic match on teacher expectations. Econ. Educ. Rev. 2016, 52, 209-224. [CrossRef]

145. Griffith, A.N.; Hurd, N.M.; Hussain, S.B. "I Didn't Come to School for This": A Qualitative Examination of Experiences with Race-Related Stressors and Coping Responses among Black Students Attending a Predominantly White Institution. J. Adolesc. Res. 2019, 34, 115-139. [CrossRef]

146. Gershenson, S.; Papageorge, N. The power of teacher expectations: How racial bias hinders student attainment. Educ. Next 2018, $18,64-71$.

147. Chávez, K.; Mitchell, K.M. Exploring bias in student evaluations: Gender, race, and ethnicity. PS Political Sci. Politics 2020, 53, 270-274. [CrossRef]

148. Rivera, L.A.; Tilcsik, A. Scaling down inequality: Rating scales, gender bias, and the architecture of evaluation. Am. Sociol. Rev. 2019, 84, 248-274. [CrossRef]

149. Robbins, S.B.; Lauver, K.; Le, H.; Davis, D.; Langley, R.; Carlstrom, A. Do psychosocial and study skill factors predict college outcomes? A meta-analysis. Psychol. Bull. 2004, 130, 261-288. [CrossRef] 